\title{
Comparing the traditional and constraints-led approaches to skill acquisition in tennis
}

\author{
Luke Regan
}

The Sports Think Thank, United Kingdom.

\section{ABSTRACT}

The following article aims to highlight the differences between a traditional or 'information processing' approach to skill acquisition and the 'constraints-led approach'. The terms are defined then various aspects of each method are considered in the context of tennis coaching. Practical examples of using the constraints-led approach are then given.
Key words: skill acquisition, constraints, self-organisation

Received: 19 June 2021

Accepted: 10 July 2021

Corresponding author: Luke Regan. Email: Iwgregan@gmail. com

\section{INTRODUCTION}

While many schools of thought exist on the most effective methods by which one can teach motor skills, they can be broadly divided into two categories: 'information processing' (IP) approaches and 'ecological' approaches, the foremost of which is the constraints-led approach (CLA). IP refers to what could be termed the 'traditional' method of direct, explicit instruction based on expert knowledge of 'correct' technique or tactics, honed through a high volume of repetition, for instance as recommended by Fitts \& Posner's (1979) cognitive-associative-autonomous stages model of skill acquisition. The CLA is an approach to skill acquisition that views skill as evolving adaptation to a dynamic environment, harnessing constraints around which the athlete is encouraged to self-organise. The ensuing technical and tactical solutions arrived at then constitute a unique fit between the current environment and the individual qualities or 'intrinsic dynamics' of the athlete.

\section{DISCUSSION}

\section{Self-Organisation}

The IP model of learning is based on a dualist assumption of mind and body (Woods, McKeown, Rothwell, Araújo, Robertson and Davids, 2020). It can be likened to a computational model of behaviour whereby motor programmes are created and stored in the brain, then later called upon and executed as necessary e.g. learning the ideal technique for a forehand (through interpretation of demonstrations, verbal instructions and corrections accompanied by repetition), then later performing it in competition as required. This approach has been criticised for its "organismic asymmetry" in neglecting the performerenvironment relationship (Dunwoody, 2007) and the unique importance of the ever-changing and dynamic nature of an athlete's surroundings in shaping their motor abilities.

In contrast, rather than assuming the control of a central executive in the brain issuing orders and delegating

\begin{tabular}{|c|c|c|}
\hline Individual & Environment & Task \\
\hline $\begin{array}{l}\text { Intentions: } \\
\text { Competitive/Co-operative } \\
\text { Gain advantage } \\
\text { - Apply Pressure } \\
\text { Make it harder/easier for } \\
\text { yourselffopponent } \\
\text { - Cause/avoid/get out of trouble } \\
\text { Fatigue } \\
\text { Emotion } \\
\text { Confidence } \\
\text { Motivation } \\
\text { Personality } \\
\text { Physical including coaching aids: } \\
\text { Handcuffs } \\
\text { Resistance bands } \\
\text { Occlusion/Sunglasses } \\
\text { Weights } \\
\text { Speed/agility } \\
\text { Ability } \\
\text { Experience } \\
\text { Genetics incl. handedness } \\
\text { Sociocultural } \\
\text { Injury }\end{array}$ & 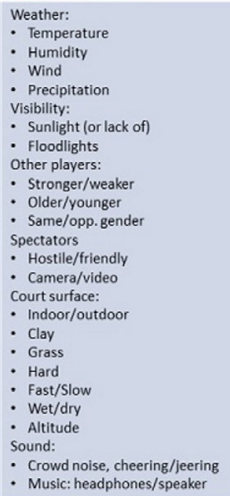 & 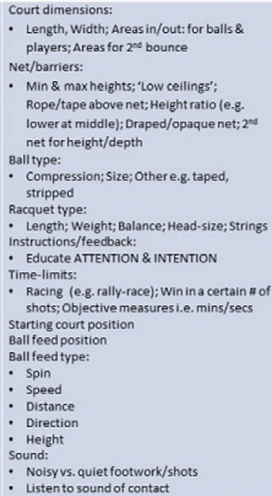 \\
\hline
\end{tabular}

Figure 1. Example table of potential constraints available to a tennis coach.

movement instructions to the limbs and musculature according to a pre-established programme, the CLA consists of treating the performer as a complex adaptive system and allowing her to self-organise around the environment in the pursuit of a task goal and a functional solution. Employing the CLA involves the manipulation of the environment and the assumption that, as each interaction between the athlete-system and the environment is unique, there is no 'optimal' technique, just individual, decentralised regulation of system components in order to satisfy the demands of each task (Chow, Davids, Button, Renshaw, Shuttleworth, \& Uehara, 2009).

\section{Constraints}

The CLA stems significantly from the work of Newell (1986) and his definition of "constraints". The term refers to the boundaries for action that arise from the interactions between the athlete's own physical and mental state (individual constraints e.g. height, mood, level of fatigue); environmental constraints (e.g. humidity, gravity, court surface); and task constraints (e.g. the equipment being used, the rules of the game, the dimensions of the court). 
The focus of the CLA is to manipulate these boundaries (most commonly those in the category of 'task' constraints), in order to guide the intention and attention of the athlete in attuning to useful information in the environment, as they search for a functional movement solution.

\section{Repetition without repetition}

Central to this process is the knowledge that in the dynamic environment of competitive sport no two movements are ever exactly the same, no shot or footwork pattern is ever precisely replicated. This knowledge necessitates the constant presence of variability in the practice environment, so that the athlete can develop versatile and adaptive movements, robust and flexible enough to satisfy a wide variety of movement problems. This is in contrast the IP aspiration of a 'champion' model for a skill, where the goal is to achieve a movement with as little deviation from the optimal technique as possible. Hence the practice mantra of the constraints-based coach or practitioner; "repetition without repetition".

\section{Instructions and feedback}

In the CLA therefore, rather than prioritising explicit information on idealised movements, verbal feedback from the coach supports the search for movement solutions by guiding intention and attention such that the athlete can more readily attune to the relevant information in the environment.

\section{EXAMPLE EXERCISES}

In this section, three examples are provided outlining possible CLA strategies to address some common issues encountered in tennis coaching. The examples below are to be juxtaposed with the typical major elements found in a traditional skill acquisition approach where the coach would look to identify technical errors then correct them with a verbal description of the desired technique followed by a demonstration from the coach, or an elite-level exemplar like a video of a professional player. This could be followed by a progression of hand-feeding, basket-feeding and rallyfeeding accompanied by a high volume of instructions, corrections and feedback on performance.

\section{Groundstroke racket-speed}

Goal: To increase the separation angle on a forehand groundstroke

Player level: Novice. Constraints used (and category):

- Cord or ribbon to bind player's hands (individual)

- Instruction (for a basket-feed) to keep toes pointed forward at all times; "imagine you're buried up to your hips in concrete" (task)

With a player who struggles to generate groundstroke racket-speed, a coach may decide to try and facilitate concentric rotation and a greater separation angle between hips and shoulders. Without resorting to explicit instruction, a constraints-led approach may employ constraints to prevent the player's arms from moving independently of each other and the upper body, thereby encouraging shoulder rotation. Simultaneously the instruction to keep the toes pointing forwards or play open-stance locks out

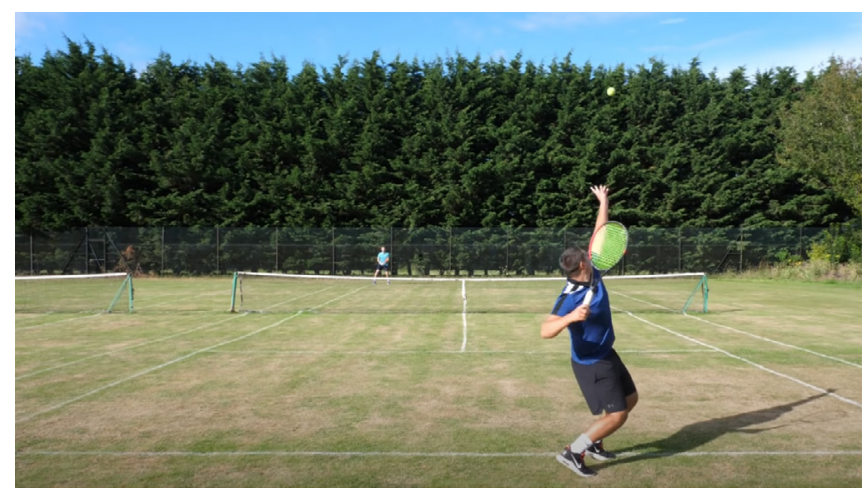

the hips and invites the solution of turning the shoulders past the hips in order to move the racket. Instructions and feedback would be used to maintain the intention of creating racket-speed ("hit hard!") and draw the player's attention to prominent kinaesthetic or auditory information in the environment, for instance the feeling of the upper and lower body moving independently, or the sound of the ball coming off the strings.

\section{Serving and volleying}

Goal: To improve a player's ability to serve and volley in singles.

Player level: Intermediate. Constraints used:

- A fast court, e.g. grass/artificial grass (environmental)

- No bounces allowed on the server's side (task)

- Court shortened and narrowed as necessary to create the optimal level of challenge for the server (task)

Used in a competitive game situation, these constraints exemplify how an environment might be designed in which a player could explore solutions to the problem of winning from the serve without letting the ball bounce on their side of the court. Although the coach would not volunteer explicit technical solutions, she would make herself available to offer help when requested and to pose questions that direct the attention of the player to relevant sources of information in the environment.

\section{Second serve}

Goal: To reduce the number of double-faults in the final set of matches

Player level: Advanced. Constraints used:

- Deliberately fatiguing the player with shuttle runs or a bleep test (individual)

- Second serves only rule for the server in a practice set (task)

A tendency to double-fault in the final set of a match could of course be due to a number of reasons. Part of a constraints-based solution might be to create a representative environment that allows the player to explore solutions to serving when fatigued. As a player's individual constraints can change during the course of a match (dehydration, increase of lactic acid, loss of concentration) she is effectively playing with a different body to that with which the match was started, therefore a different second-serve solution is required. Such a solution 


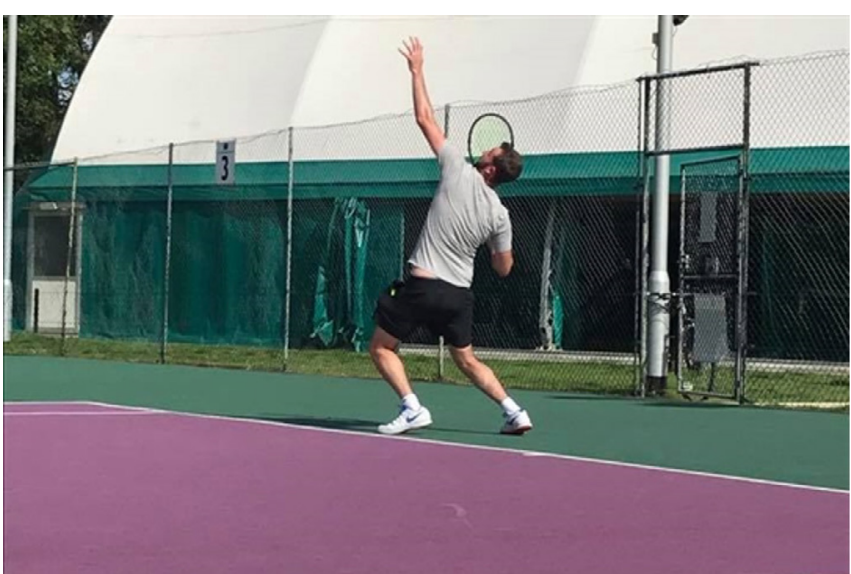

can be arrived at without direct prescription from a coach, just through giving the player a high volume of chances to adapt their serve by self-organising in a constrained environment.

\section{CONCLUSION}

Manipulating constraints is not new to coaching per se, coaches have always utilised tasks and environments in ostensibly similar ways. But in order to maximise their effectiveness, the CLA and its theoretical foundations provide a basis for using constraints in a way that assumes a model of behaviour profoundly different from the traditional, cognitive approach of transforming 'one size fits all' technical information into procedural knowledge. The use of constraints to impact behaviour change will not be optimal if deployed as part of a prescriptive coaching style. The CLA is the use of interacting constraints to facilitate the emergence of functional behaviour through self-organisation, not to simply provide opportunities for a player to execute a pre-established technique dictated by a coach.

Ongoing developments in psychological theory are continuously informing best practice in skill acquisition and, far from being locked into the assumption that skills can only be coached through the prescriptive transmission of expert information, coaches are encouraged to explore more ecological and implicit approaches to developing skill in tennis players.

\section{REFERENCES}

Chow, J., Davids, K., Button, C., Renshaw, I., Shuttleworth, R., \& Uehara, L. A., (2009). Nonlinear pedagogy: implications for teaching games for understanding (TGfU). In: TGfU: Simply Good Pedagogy: Understanding a Complex Challenge, 14-17 May 2008, University of British Columbia, Vancouver.

Dunwoody, P.T. (2007). The neglect of the environment by cognitive psychology. Journal of Theoretical and Philosophical Psychology, 26, 139-153.

Fitts, P.M. \& Posner, M.I. (1979). Human Performance. Belmont, CA: Brooks/ Cole.

Gray, R. (2020). Comparing the constraints led approach, differential learning and prescriptive instruction for training opposite-field hitting in baseball. Psychology of Sport \& Exercise, 51, 101797.

Newell, K. (1986). Constraints on the development of coordination. Motor development in children: Aspects of coordination and control.

Woods, C.T., McKeown, I., Rothwell, M., Araújo, D., Robertson, S., and Davids, K. (2020). Sport practitioners as sport ecology designers: how ecological dynamics has progressively changed perceptions of skill "acquisition" in the sporting habitat. Frontiers in Psychology, 11:654. transform, and build upon the material for any purpose, even commercially under the following terms:

Attribution: You must give appropriate credit, provide a link to the license, and indicate if changes were made. You may do so in any reasonable manner, but not in any way that suggests the licensor endorses you or your use. 